\title{
EL PERSONAJE SINGULAR: UN ASPEGTO DEL TEATRO DEL SIGLO DE ORO
}

"La característica genérica del teatro español es, por supuesto, el hecho de que se trata esencialmente de un teatro de acción y no de caracterización. No se retratan personajes redondeados y completos, aunque ciertas obras lo hacen incidentalmente... El teatro español parte del presupuesto - respaldado, después de todo, por la autoridad de Aristóteles- de que la trama, y no los personajes, es lo principal... En general, la caracterización de las piezas teatrales españolas es esquemática".

Estas palabras de Alexander A. Parker, a la vez que reflejan una idea ya antes generalizada, forman parte de su concepción particular del teatro español, tal como la expuso en su fundamental ensayo The approach to the Spanish drama of the Golden Age ${ }^{1}$, que ha tenido amplias y profundas repercusiones en las últimas dos décadas. Si algunos de los cinco "principios" que ahí establece Parker han sido sometidos a crítica, éste, que es el primero, se ha mantenido intacto hasta ahora; R. D. F. Pring-Mill, por ejemplo, habla también de "la naturaleza tan esquemática de la caracterización en la mayoría de las comedias del Siglo de Oro" 2. Parker y Pring-Mill son cautos - "certain plays may do so incidentally", "la mayoría de las comedias"-, pero el hecho es que la idea general sigue en pie, y eso a pesar de que en buen número de estudios se menciona o incluso se examina detenidamente la elaborada caracterización de determinados personajes ${ }^{3}$.

1 Londres, 1957 (serie Diamante); reproducido en TDR, 4 (1959), pp. 42. 59 (utilizo esta segunda impresión); la cita, pp. $42-43$ (la traducción es mía).

2 En su reseña de "The approach...", $R J, 13$ (1962), p. 384; cf. además su Introducción a Lope de Vega (Five plays), trad. J. Booty, New York, 1961, p. xiv: "The subordination of characters to action is... a deliberate technique". Aunque parte de un enfoque distinto, Arnold G. Reichenberger, en un artículo también ya clásico, dice que "the code-bound Spanish theater made the development of individual character difficult and rare" ("The uniqueness of the comedia", HR, 27, 1959, p. 311).

3 Podría citarse como un ejemplo el reciente artículo de T. A. O'Connor, 
Que yo sepa, sólo C. A. Jones, en un artículo de 1965, ha examinado la cuestión, aunque sin ponerla a discusión expresamente. El alcalde de Zalamea, dice, se ha considerado como obra excepcional por su "verdadero interés en la caracterización", pero "la obra no es, de hecho, tan excepcional... Este interés en los seres humamanos y su conducta es... evidente en muchas más piezas de Calderón y de otros autores del Siglo de Oro de lo que los historiadores y críticos de la literatura han tendido a observar" ${ }^{4}$. Es verdad que en la comedia española no hay "gigantes como Hamlet, Otelo o Lear, o incluso como el Cid o Fedra", pero Calderón comparte con Shakespeare y Racine la misma "preocupación subyacente", la de crear personajes que "en última instancia nos conmueven por su humanidad; porque, aun siendo únicos, se ven movidos por los mismos impulsos y deseos que nosotros" (pp. $38 \mathrm{~s}$.). Jones aboga así por el reconocimiento de un cierto grado de caracterización en muchas obras teatrales, y por la universalidad de determinados personajes. Establece, sin embargo, una distinción entre los grandes dramaturgos europeos y Calderón: en éste "humanity is illustrated through the relative anonimity of the characters rather than through their unique individuality" (p. 39).

Surge una pregunta: ¿cómo se explica la poderosa impresión que dejan en nosotros ciertos protagonistas y aun ciertos personajes secundarios de la comedia española? ¿Por qué Pedro Crespo y don Lope de Figueroa, por qué Juan Labrador, don García (La verdad sospechosa), la Serafina del Vergonzoso en palacio, la dama boba, o un héroe trágico como don Gutierre, el médico de su honra, se graban en nuestra memoria con más fuerza que la trama misma de las obras correspondientes?, ¿por qué al recordarlas lo que se nos viene a la mente son esos personajes? ¿Sería posible tal cosa si su caracterización fuera "esquemática", si, como dice también Parker, se limitara a "breves toques" a "insinuaciones" y "detalles sugeridos" 5 ? ¿Sería posible si los personajes fueran relativamente "anónimos" y carecieran de una "individualidad única"?

Antes de contestar estas preguntas, conviene asomarse a un aspecto de la teoría literaria neo-aristotélica que imperó en el Siglo de Oro, aspecto del que se habla poco en nuestros días. Glosando

"The interplay of prudence and imprudence in $E l$ médico de su honra", $R J$, 24 (1973), 303-322.

4 C. A. Jones, "Spanish honour as historical phenomenon, convention and artistic motive", $H R, 33$ (1965), 32-39; la cita, pp. 34 s. (traducción mía).

5 PARker, art. cit., pp. 42-43: "The dramatists... must confine their characterization to brief touches. They left it to the audience and the actors to fill in, from these hints and touches, the psychology of the characters... The details are suggested but not necessarily filled in, and our imagination, as we read or listen, must construct the rounded character". 
a Aristóteles, el Pinciano enumera los tres requisitos que debe tener todo argumento literario: "La fábula debe ser: 1) una y varia, 2) perturbadora y quietadora de los ánimos, y 3) admirable y verisímil" ". Debe ser a dmi r a b le, es decir, sorprendente; para lograrlo, para causar "admiración", debe tratar de "algún acaecimiento nueuo y raro" (p. 57) ; el poeta ha de ser "en la inuención nueuo y raro; en la historia, admirable, y en la fábula, prodigioso y espantoso" (p. 58).

López Pinciano, como Aristóteles, se refiere específicamente a la historia, a la fábula narrada o representada. En efecto, la literatura narrativa y dramática del Siglo de Oro abunda en historias extraordinarias, nuevas y raras ", "admirables", "prodigiosas y espantosas". Pero la doctrina de la admiratio se ejercía también en otros niveles de la obra literaria. Wardropper la ha encontrado vigente en ciertas metáforas básicas del teatro de Calderón, que resultan nuevas, extrañas, osadas ${ }^{8}$, y Montesinos dice de la erudición de Lope que "responde al propósito de todo lo barroco: sorprender, maravillar. No se trata ya sólo de saber mucho; se trata de saber cosas que no sepa nadie" ${ }^{\text {. }}$.

Espero poder mostrar que otro nivel donde este afán de sorprender y maravillar está a la vista es la caracterización, tal como se da en buen número de comedias y tragedias. Los personajes a que he aludido y otros muchos adquieren relieve porque están marcados por un rasgo peculiar que no se encuentra comúnmente en los seres normales, al menos no de manera tan concentrada. Esa peculiaridad puede ser parte de su personalidad o puede surgir en un momento dado, por las circunstancias que los envuelven; en todo caso, los singulariza y los convierte en objeto de "admiración". Lo extraño de su personalidad y de su conducta, al limitarse a una determinada característica, impide, en general, que sean personajes redondeados, complejos y completos, y en esto tiene razón Parker. Pero por otra parte, como tendremos ocasión de ver, su sola pre-

- López Pinciano, Philosophia antigua poetica, ed. A. Carballo Picazo, Madrid, 1953 (Biblioteca de antiguos libros hispánicos, 19-21), t. 2, p. 39.

7 Pienso que sólo en un nivel de gran abstracción puede decirse, con Reichenberger, que "the Spanish dramatists [dramatize] only a very limited number of conflicts in a great number of plays", art. cit., p. 305.

s En los autos sacramentales, dice Wardropper, "the image often is unheard. of, new, daring"; en El médico de su honra la metáfora es "startling", por ser transformación novedosa de un topos tradicional: "The theme has become $R e$. media honoris, not amoris; the emphasis has shifted from the patient to the agent (the physician, not the sick man, has the problem)" ("Poetry and drama in Calderón's El médico de su honra", RR, 49 (1958), 3-11).

9 José F. Montesrnos, "La paradoja del "Arte nuevo», en sus Estudios sobre Lope, 2a ed., Madrid, 1967, p. 8. 
sencia y actuación suele incidir en forma decisiva en la "fábula", de tal manera que en esas obras el principio parkeriano de "la supremacía de la acción sobre la pintura de caracteres" ${ }^{10}$ queda en entredicho.

En El villano en su rincón se producen dos hechos extraños: hay un labrador, rico y estimado, que se niega a ver al rey cuando éste pasa -y pasa a menudo- por su aldea, y hay un rey que se inquieta por ese desprecio de su súbdito y que decide presentarse ante él para obligarlo a que lo vea. Encontramos en la comedia otros hechos novedosos, pero estos dos son los más notables, y ambos descansan en los personajes. En cuanto a Juan Labrador, su extravagante conducta se debe a una excentricidad connatural, persistentemente manifiesta en sus palabras y acciones y muy comentada, con sorpresa, crítica o veneración, por otros personajes. Dice Juan Labrador a su hijo:

Yo propuse, Feliciano,

de no ver al Rey jamás, pues de la tierra en que estás

yo tengo el cetro en la mano (I, 495-498 ${ }^{11}$ ),

y Feliciano comentará indignado que el mundo no ha producido un hombre más bárbaro (vs. 537 ss.), lo llamará "monstruo" (588), hablará de su "villanía" (548) y de su "rudeza" (618) y concluirá que "ni aun hombre mereció ser" (634). Lisarda, la hija, reaccionando con más serenidad y humor:

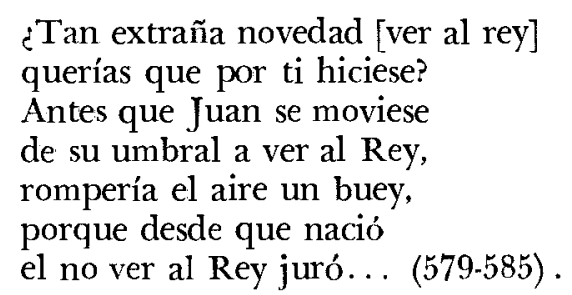

En cuanto al rey, su inesperada reacción -Finardo se escandaliza: "¿cómo envidias a un villano, / tú con el cetro en la mano, / y él con el arado allí?" (II, 78-80) ; “Eso te da pesadumbre? / ¡Un villano en su rincón!" (101 s.) - no se presenta como un rasgo de carácter, sino como impulso pasajero, momento de flaqueza humana, neutralizado después, cuando el rey asume su papel de monarca. Hay un personaje excéntrico y otro que reacciona excéntricamente

*⿻一𠃋十:

10 Parker, art. cit., p. 58.

11 Cito por la edición de B. W. Wardropper, Teatro español del siglo de Oro, New York, 1970, pp. 258-364. 
ante aquél, provocando un encuentro delicioso, en que la terca obsesión del uno compite con la tozuda obcecación del otro.

Por supuesto, Juan Labrador, con su dignidad, su serenidad, su manera de gozar la vida que Dios le ha dado y que él se ha forjado con el trabajo, es mucho más que un aldeano testarudo; sin ser un personaje "redondeado", es una figura de bulto, que pervive en nuestra memoria como tal; pero lo recordamos sobre todo por su extraña manía. Si bien lo miramos, es esta manía, esta rareza curiosa de Juan Labrador, la que echa a andar la acción principal de la comedia, es su causa primera. Si ascendemos -o descendemosal nivel del tema, podría verse en la actitud del aldeano un elemento de soberbia, y el desconcertante final podría aparecer como un acto de justicia poética. Pero Lope tuvo buen cuidado en dar a su obra la suficiente ambigüedad como para que su "sentido" -si es que quiso darle un sentido- no quedara claramente manifiesto (de ahí la diversidad de interpretaciones en nuestros días), y parte de esa ambigüedad reside en el hecho de que Juan Labrador se nos presenta como un personaje admirable -en los dos sentidos de la palabra-, que, a los ojos del espectador, no merece un castigo.

¿No ocurre, en el fondo, algo parecido en otra comedia, que es abiertamente una obra de tesis, con un tema claro y explícito, y donde la justicia poética" se ejerce sobre un personaje cuyo "feo vicio" hace, en realidad, las delicias del espectador? Me refiero a $L a$ verdad sospechosa. Lejos de ser un perverso, don García es un personaje encantador; ingenioso, imaginativo al máximo, gozando las ficciones que gratuitamente se inventa, divirtiéndose como un niño con las "niñerías éstas / ordenadas de repente" (I, $765^{12}$ ), deja maravillado no sólo a Tristán - “Válgate el diablo por hombre! / iQue tan de repente pueda / pintar un convite tal / que a la verdad misma venza!" (I, 753-756) -: maravilla al público entero. Si Tristán lo censura, si el padre preferiría verlo muerto a verlo mentiroso, el espectador, en cambio, se deleita con sus geniales improvisaciones, como, visiblemente, se deleitó Juan Ruiz de Alarcón al escribirlas.

Se trataba, sin embargo, de dar una lección, y así Alarcón le impuso a su comedia un final que deja maltrecho a su protagonista, tan amorosamente creado. Final postizo, en cierta medida, puesto que el enredo que lleva al desenlace no es sólo obra de las mentiras de don García, sino también del azar (el quid pro quo del principio, el hecho de que el padre de don García quisiera casarlo precisamente con Jacinta, el trueque de billetes en III, 2424 ss.) y además de las maquinaciones de Jacinta (cf. I, 1025 ss. y el comienzo del acto II). La moraleja - el tema- de la comedia va, pues,

12 Ed. Alfonso Reyes, 3a ed., Madrid, 1937 (Clis. casts., 37). 
por un lado y por otro va su sustancia misma, la personalidad sabrosamente estrambótica de don García y los enredos que ella y las circunstancias originan. Basta comparar La verdad sospechosa con otra obra de tesis, con El burlador de Sevilla -don Juan es congruente e irremediablemente malo-, para darnos cuenta de la contradicción implícita en la comedia de Alarcón, o, si se quiere, de los dos planos distintos en que se mueve.

Sólo artificialmente se subordina, en esta pieza, la acción al tema (el segundo principio de Parker). En cuanto a la relación entre acción y caracterización, dada la importancia del enredo resulta difícil decir qué se subordina a qué. Pero no hay duda de que aquí nos las tenemos que haber con un personaje altamente caracterizado, y, otra vez, caracterizado sobre todo en una dirección, marcado con un rasgo peculiar, raro, "admirable", y así, "deleitoso".

Las dos figuras femeninas de la obra, Jacinta y Lucrecia, también están, hasta cierto punto, singularizadas -aunque dentro de los cánones de la normalidad-, y lo están por el contraste que existe entre sus personalidades. Tal caracterización por contraste se da en otras parejas femeninas del teatro español, y puede ocurrir que una de las dos damas - personaje principal o secundario-presente rasgos extraños. Es el caso de la Serafina de $E l$ vergonzoso en palacio. Si el protagonista, Mireno-don Dionís, es una figura un tanto desdibujada ${ }^{13}$, Serafina tiene una personalidad fuerte e inquietante. Esta hermosa desamorada desearía haber nacido varón:

no te asombre que apetezca el traje de hombre, ya que no lo puedo ser (II, 736-738).

En la espléndida escena del jardín ensaya un papel masculino, y con tanta entrega, que se transforma realmente en el personaje representado, atemorizando a su acompañante. Finalmente, se enamora del retrato donde aparece vestida de hombre. Doña Juana exclama:

\section{|hay más singular \\ suceso! Castigo ha sido}

13 Hay dos Mirenos: el que, al principio, imbuido de una poderosa voluntad, se lanza a contrarrestar su adversa fortuna ("cuanto más me hiciere yo, / más vendré a deberme a mí, I, 401 s.; "No soy, seré, / que sólo por pretender / ser más de lo que hay en mí, / menosprecié lo que fui / por lo que tengo de ser”, I, 1035-1039; cito por la ed. de Américo Castro, Madrid, 1922; Clás. casts., 2) y el que, una vez llegado a palacio y favorecido por Madalena, se muestra en extremo pusilánime. Se diría que un "vergonzoso en palacio" no debía haberce pintado en el primer acto con taleṣ rasgos de decisión y arrojo. 
del cielo que a su retrato

ame quien a nadie amó! (III, 888-891) .

Más que el "suceso", es singular la configuración psicológica de este personaje, al cual la maestría de Tirso ha desarrollado hasta el punto de convertirlo en la figura de más relieve en la obra, a pesar de que no está siquiera relacionada, más que tangencialmente, con su acción principal. $\mathrm{Y}$ esto es tan cierto, que lo que hay de justicia poética en esta obra, además de la reivindicación final del Duque de Coimbra y de Ruy Lorenzo, se ejerce sobre Serafina, la cual acaba sabiendo que el retrato era suyo y teniendo que casarse con el aborrecido don Antonio.

Otra pareja femenina contrastante es la de Finea, la dama boba, y su hermana Nise; una y otra son "palma y roble",

pues Nise bella es la palma;

Finea un roble, sin alma

y discurso de razón.

Nise es mujer tan discreta, sabia, gallarda, entendida, cuanto Finea encogida, boba, indigna y imperfecta (I, 122-127 14).

Lope desarrolla deliciosamente la extraña bobería de Finea, para después, en un coup de théatre, hacer que esa bobería se torne discreción e ingenio por obra del amor. Lo "admirable" de este caso está por un lado en la exagerada -cómicamente patológica- simpleza de la protagonista y por el otro en su transformación, que se sitúa en el nivel de la fábula, pero que a la vez se ejerce en el plano de la caracterización. Finea juega ahora con sus dos personalidades, fingiéndose boba cuando las circunstancias lo requieren, tal como, en un plano más profundo, Serafina ha jugado el papel que le hubiera gustado desempeñar en la vida. Otro de nuestros personajes, don García, la ha hecho de actor a lo largo de la comedia, sólo que aquí la ficción es consustancial con el carácter del personaje. $\mathrm{Su}$ desenfrenada imaginación lo lleva a reinventar su vida una y otra vez. Es, por supuesto, una ficción deliberada, que contrasta con la ficción involuntaria que una imaginación calenturienta suele imponer a algunos héroes trágicos del teatro español ${ }^{15}$.

Quisiera detenerme en uno de ellos, en don Gutierre Alfonso Solis, el protagonista de El médico de su honra. Es un personaje de gran estatura, que, como pocos, incita a cuestionar nuevamente las

14 Ed. de A. Zamora Vicente, Madrid, 1963 (Clais, casis., 159).

15 Cf. B. W. WARdropper, "La imaginación en el metateatro calderoniano", $C H(3), 923-930$ y, en versión parcialmente retocada, $H R L(2), 613-629$. 
relaciones que se han establecido entre tema, acción y caracterización. Es útil a este respecto una comparación entre $E l$ médico y $E l$ pintor de su deshonra, porque, tratándose de fábulas análogas, la configuración de las dos obras es radicalmente distinta. En El pintor Calderón ha desarrollado una trama compleja, rica en incidentes, dejando poco margen para la vida interior de los personajes; la de don Juan Roca, el marido deshonrado, está apenas apuntada; en El médico, en cambio, casi todo el peso recae en los tormentos anímicos de don Gutierre. No es su personalidad, como tal, la que está en juego, por más que el episodio con doña Leonor muestre ya un rasgo - un exceso de suspicacia en cuestiones de honor- que lo marca, anticipando (y haciendo verosímil) lo que luego le ha de ocurrir. Lo importante es su transformación interna a partir del momento en que sabe que ha entrado un hombre al aposento de Mencía. Se entabla entonces una lucha a muerte entre su cordura y una pasión irracional que lo enloquece.

Sigamos paso a paso la batalla. Cuando doña Mencía, para "curarse en salud" (II, $223^{16}$ ), decide revelar la presencia de un hombre, don Gutierre, noble, sensato, bondadoso, reacciona con asombro (281 s.) y terror ("Todo soy hielo", 284). Cuando sabe que el hombre ha escapado, estalla la alteración de su ánimo:

¡Oh ciego abismo

del alma y paciencia mía! (309 s.).

Tras el hallazgo de la daga decide disimular para poder reflexionar sobre lo que le está ocurriendo:

Ay, honor, mucho tenemos

que hablar a solas los dos! (381 s.).

Hay una pausa - diálogos del rey con don Diego y con Coquín y de ambos con el Infante-, y don Gutierre reaparece en escena, en el alcázar de Sevilla; el cotejo de la daga con la espada de don Enrique le revela quién es el hombre que ha penetrado en su casa. La deseada soledad provoca el primer gran monólogo de don Gutierre ${ }^{17}$. En palabras y en lágrimas sale a raudales la emoción repri-

16 En B. W. Wardropper (ed.), Teatro español..., op. cit., pp. 495-609.

17 "Ya estoy solo, ya bien puedo / hablar", dice (II, 565 s.), como antes, en I, $121 s$., doña Mencía al quedarse sola con el cuerpo inerte del Infante ("Ya se fueron; ya he quedado / sola"). El paralelismo continúa; Mencía: "¡Oh, quién pudiera dar voces / y romper con el silencio / cárceles de nieve, donde / está aprisionado el fuego", 125-128; y don Gutierre, en II, 566 ss.: "Ay Dios!, iquién pudiera / reducir sólo a un discurso, / medir con sola una idea / tantos géneros de agravios...". 
mida. Pero pronto se reporta ("cese el sentimiento", II, 585) y se impone un análisis desapasionado y sistemático de los hechos. "En cuanto a que...; en cuanto a que...; en cuanto a que..." (599 ss.). Cada cosa podría tener una explicación que dejaría a salvo su honor; pese a las evidencias, Mencía "pudiera no estar culpada"; aún más, concluye, satisfecho de sus razonamientos, "todos juntos se cierran / en que Mencía es quien es, / y soy quien soy" (628-630). Sin embargo, el dolor ha ido irrumpiendo en la impecable sensatez de su discurso:

$$
\begin{aligned}
& \text { En cuanto ( } \text { ay dolor mío!) } \\
& \text { que con la espada convenga } \\
& \text { del infante... (609-611), } \\
& \text { confieso (jay de mí!) que sea } \\
& \text { del infante... (616 s.), }
\end{aligned}
$$

y, apenas afirmada la pureza del honor de Mencía - "No hay quien pueda / borrar de tanto esplendor / la hermosura y la pureza" (630. 632) -, se instala, implacable, la certidumbre de la deshonra:

Pero sí puede, mal digo;

que al sol una nube negra, si no le mancha, le turba... (633-635).

Y, dirigiéndose otra vez a su honor como ente personificado:

$$
\begin{aligned}
& \text { A peligro estáis, honor, } \\
& \text { no hay hora en vos que no sea } \\
& \text { crítica... (639-641). }
\end{aligned}
$$

En seguida, la decisión: "Yo os he de curar, honor" (645).

Al parecer, la razón sigue imperando en don Gutierre cuando planea minuciosamente la táctica que habrá de seguir para curar su honra, asumido ya del todo su papel de médico:

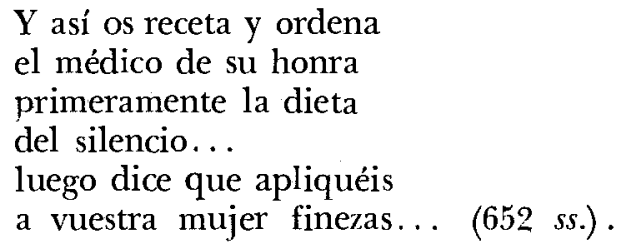

Pero la pasión, agazapada tras de la frialdad del raciocinio, no tarda en desbordarlo:

disimularé, si puedo, esta desdicha, esta pena, 
este rigor, este agravio, este dolor, esta ofensa, este asombro, este delirio, este cuidado, esta afrenta, estos celos... (671-677),

y aterrado por el involuntario desbordamiento:

¿Celos dije?

¿Qué mal hice! Vuelva, vuelva

al pecho la voz...

¿Celos dije? ¿Celos dije? (677-679, 687).

Con toda la fuerza de su voluntad, levanta un dique:

Pues basta; que cuando llega

un marido a saber que hay

celos, faltará la ciencia (688-690).

La "ciencia" ya ha faltado y es irrecuperable; el delirio se ha adueñado de don Gutierre y manejará sus acciones, por más que él piense tenerlas sujetas a la razón. Como dice Daniel Rogers, "Jealousy... has crept in and taken unlawful possession of Don Gutierre's heart and mind" 18.

Nuevamente la entrada en escena de otros personajes --don Arias y doña Leonor- interrumpe ante nuestros ojos el drama interno del protagonista. Cuando volvemos a ver a don Gutierre está saltando las tapias de su casa:

En el mudo silencio

de la noche, que adoro y reverencio,

por sombra aborrecida,

como sepulcro de la humana vida,

de secreto he venido... (841-845).

Ya el comienzo del monólogo muestra la profunda alteración de su ánimo y a la vez su certidumbre de que la "ciencia" sigue imperando en sus acciones:

18 "Tienen los celos pasos de ladrones: silence in Calderón's El médico de su honra", HR, 33 (1965), 273-289, y en Pedro Calderón de la Barca, Comemedias, t. 19, Critical studies of Calderón's comedias, ed. J. E. Varey, London, 1973; la cita, tomada de $H R$, p. 283. Cf. B. W. WARDROPPER, "The implicit craft of the Spanish «comedia", HEMW, 339-356, p. 349: "Don Gutierre turns anxiously, even crazily, to his restless, disturbed mind to find a solution. After much ratiocination he concludes that his honour... is sick. Accordingly, acting like a physician, he must cure his sick honour". 
Médico de mi honra me llamo, pues procuro mi deshonra curar; y así he venido a visitar mi enfermo a hora que ha sido de ayer la misma (jcielos!), a ver si el accidente de mis celos a su tiempo repite:

el dolor mis intentos facilite (851-858).

Ha dicho "celos", ha dicho "dolor", y sabe en ese momento que todo control racional de los sentimientos es ilusorio:

... ¡Ay Dios, qué introducido engaño es en el mundo no querer su daño examinar un hombre, sin que el recelo ni el temor le asombre! Dice mal quien lo dice; que no es posible, no, que un infelice no llore sus desvelos; mintió quien dijo que calló con celos, o confiéseme aquí que no los siente (861-869).

Cuando en seguida descubre a doña Mencía durmiendo, retoma su papel de médico con aparente cordura - "Bueno he hallado mi honor, hacer no quiero / por ahora otra cura, / pues la salud en él está segura" (880-882). ¿Está segura?, se pregunta, acosado otra vez por los celos, pero pasa abruptamente a censurarse a sí mismo por sus sospechas - " $\mathrm{OOh}$ pensamiento / injusto! ¡oh vil temor! ¡oh infame aliento!" (885 s.) -, y luego, sin transición, asume de lleno su desvarío:

Mato la luz y llego

sin luz y sin razón, dos veces ciego (891 s.).

La crueldad de la escena que sigue (Mencía confunde a don Gutierre con el Infante) no puede sino minar lo que aún queda de sensatez en el protagonista; su voluntad de control se funde con el tormento en la ambigüedad de su discurso. Pero basta una palabra de Mencía, basta la alusión a los celos - "Parece que celoso / hablas en dos sentidos" (99l s.) - para desencadenar en don Gutierre toda la locura contenida:

Don Gutierre: ¡Celoso! ¿Sabes tú lo que son celos? Que yo no sé qué son, ¡viven los cielos! Porque si lo supiera, y celos 
Doña Mencía: Don GutierRe:
(jAy de míl)

a tener - ¿qué son celos?

llegar pudiera

átomos, ilusiones y desvelos-

no más que de una esclava, una criada,

por sombra imaginada,

con hechos inhumanos

a pedazos sacara con mis manos

el corazón, y luego,

envuelto en sangre, desatado en fuego,

el corazón comiera

a bocados, la sangre me bebiera,

el alma le sacara,

y el alma, ¡vive Dios!, despedazara,

si capaz de dolor el alma fuera (995-1011) ${ }^{19}$.

Aterrado de este "outburst of imprecedent savagery" ${ }^{20}$, vuelve en sí:

Pero ¿cómo hablo yo desta manera?

¡Jesús, Jesús mil veces!

Mi bien, mi esposa, cielo, gloria mía,

ah mi dueño, ah Mencía,

perdona, por tus ojos,

esta descompostura, estos enojos;

que tanto un fingimiento

fuera de mí llevó mi pensamiento (1012-1020).

Es el final del segundo acto; sus últimos dos versos son un aparte de don Gutierre: "Pues médico me llamo de mi honra, / yo cubriré con tierra mi deshonra" (1027 s.). Al comienzo del tercer acto don Gutierre aparece en el alcázar de Sevilla ante el rey. Turbado, llorando, viene a pedir justicia contra el Infante. En un último y desesperado intento de cordura, trata de prevenir el asesinato de su esposa, dejando a don Pedro la responsabilidad de restaurar el honor perdido:

La vida de vos espero

de mi honra: así la curo

con prevención, y procuro

que ésta la sane primero (III 41-44),

19 Se repite, pero centuplicada, la reacción ante el inconsciente brotar de la palabra celos en su propio parlamento de II, 677-687. Sin embargo, hay que notar que entre tanto él mismo se ha confesado que está celoso; inmediatamente antes de despertar a Mencía ha dicho tres veces la palabra, sin que lo hiciera estallar, como ahora cuando la pronuncia Mencía.

20 D. ROGERS, art. cit., p. 283. 
aunque nuevamente la idea provoca en él un desbordamiento irracional, en que reaparecen como en eco palabras que ha dicho antes:

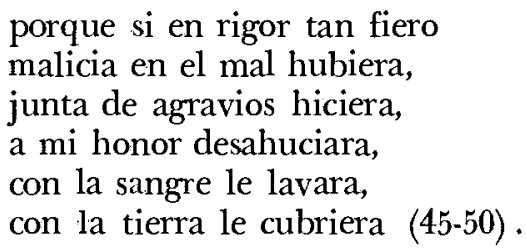

Y ante la turbación del rey, finge: "No os turbéis: con sangre digo / solamente de mi pecho; / que Enrique, estad satisfecho, / está seguro conmigo" (51-54). Haciendo un supremo esfuerzo, inventa ante el rey la inocencia de Mencía; sólo se trata, dice, de imaginaciones, de sospechas, de recelos. Y otra vez:

Sólo a vuestra majestad
di parte, para que evite
el daño que no hay; porque
si le hubiera, de mí fíe
que yo le diera el remedio
en vez, señor, de pedirle (87-92).

(Por tercera vez, el esquema "no..., porque si sí...").

La aparición de don Enrique, la terrible y ambigua escena entre él y el rey, mientras Gutierre escucha escondido, la herida que involuntariamente hace el Infante a don Pedro y la exaltada -presagiosa- reacción de éste, frustran la prevención de don Gutierre, quien en ese momento decide definitivamente la muerte de Mencía:

Arranquemos de una vez

de tanto mal las raíces.

Muera Mencía... (255-257).

Y aún quisiera que no ocurriera la tragedia, que el cielo le enviara un piadoso rayo para matarlo; aún hace falta que el azar y la última imprudencia de Mencía ${ }^{21}$ lleven a sus manos otra "prueba" de su deshonra, para que la decisión tome cuerpo y el médico de su honra, reinstalado en su papel, planee - como antes- la táctica que ha de emplear ("Mas esto ha de pensarse desta suerte...", 421 ss.).

La frialdad con que procede, su complacido análisis de la situación mientras Ludovico ejecuta la masacre ("Haber traído a este hombre / con recato semejante / fue bien, pues...", "Éste fue el más fuerte medio...", "ninguno podrá probarme / lo contrario...", 558-581) y la tranquila aseveración final,

2t Cf. el artículo de O'Connor cit, supra, nota 3. 
Médico soy de mi honor:

la vida pretendo darle

con una sangría; que todos

curan a costa de sangre (582-585),

se sitúan ya plenamente en el ámbito de la locura; ella ha ganado al fin la larga y penosa batalla. Cuando don Diego ve a don Gutierre después del asesinato, dice:

\section{Loco furioso \\ don Gutierre de su casa \\ sale (770-772).}

Tanto se ha discutido sobre el ambiguo final del Médico de su honra en términos de justicia poética: ¿le dio el rey don Pedro carta de legitimidad al homicidio perdonándole la vida a don Gutierre y casándolo con doña Leonor? ¿Cómo juzgó el rey lo ocurrido? Sus palabras parecen impresionantemente contradictorias. Al enterarse del asesinato, dice, en un mismo aparte, "acción tan inclemente", pero "cuerdamente / sus agravios satisfizo" (III, 743-745) y en otro aparte (827), "tomó notable venganza", lo que suena también a elogio. En seguida, cuando don Gutierre intenta evadir el matrimonio con Leonor arguyendo que nuevamente podría ocurrir "que de noche halle embozado / a vuestro hermano en mi casa" (856 s.), que encuentre "tal vez, señor, / de don Enrique la daga" (860 s.) y que vea "rondar después / de noche y de día mi casa" (866 s.), el rey replica tajante: "No dar crédito a sospechas", "apelar a la cordura", "quejárseme a mí". Pero súbitamente:

-Para todo habrá remedio.

$$
\text { -¿Cuál, señor? }
$$

- Uno vuestro.

-¿Qué es?

$$
\text { -Sangrarla (878-881). }
$$

¿Cómo explicar este caótico ir y venir entre una aparente condena y una aparente aceptación?

Decía el Pinciano: "Será mejor la tragedia que... fuere pathética, porque el deleyte viene a la tragedia de la compassión del oyente, y no le podrá tener si el agente no parece estar muy apassionado... Es, pues, la mejor tragedia la pathética, porque más cumple con la obligación del mouer a conmiseración, y si tiene el fin desastrado y miserable, es la mejor" 22 . La tragedia de don Gutierre y

22 Lóptz Pinciano, op. cit., t. 2, pp. 320, 322. Cf. A. I. Watson, "El pintor de su deshonra and the Neo-Aristotelian theory of tragedy", en B. W. WAR- 
doña Mencía tiene un fin desastrado y miserable; El médico de su honra, no; entre los dos finales se interpone el perdón del rey. ¿No será porque el personaje don Pedro, espectador del mundo de sus súbditos ${ }^{23}$, ha sentido por don Gutierre la misma conmiseración que los espectadores de la obra? ¿No encontraríamos así un sentido a lo que parece no tenerlo a fuerza de ambigüedades? El rey, como el público, queda espantado por la "acción tan inclemente", impresionado por la "notable venganza" ${ }^{24}$. Cuando habla con don Gutierre le hace ver su verdadera opinión: ha obrado precipitada e insensatamente; cuando luego, en forma sorpresiva, le aconseja que repita el asesinato si su segunda mujer le es infiel, parece haber comprendido que ese hombre desdichado está más necesitado de piedad que de lecciones de cordura (las cuales, además, no es ya capaz de escuchar). Si esta lectura es acertada, no habría en la obra justicia poética; en ella funcionarían simplemente las leyes de la tragedia patética.

Don Gutierre es un héroe trágico. Aristóteles, como dice el Pinciano, quiere que la persona trágica "sea de tal condición que por algún error aya caydo en alguna desuentura y miseria especial" ${ }^{25}$. El "error" de don Gutierre consiste en que le ha "faltado la ciencia" 26 , en que ha dejado que la pasión de los celos turbara su en-

DROPPER (ed.), Critical essays on the theatre of Calderón, New York, 1965, 203223: la mayoría de las obras serias del teatro del Siglo de Oro son tragedias "moratas", en las que se premia al bueno y castiga al malo, pero "we should always be on the alert for the occasional tragedia patética in which the dramatist is concerned less with punishing his hero's wickedness or rewarding his virtue than he is with arousing the tragic emotions in his audience" (p. 209).

23 Ése es uno de sus papeles en la obra; dos veces lo vemos rondando las calles de incógnito, para "saber así / sucesos y novedades / de Sevilla, que es lugar / donde cada noche salen / cuentos nuevos; y deseo / desta manera informarme / de todo..." (II, 387-393).

24 La expresión evidentemente no es elogiosa, sino que notable tiene el sentido de nuevo, raro, admirable, prodigioso, espantoso (en el vocabulario del Pinciano). Ludovico, el sangrador, después de efectuada la "cura", habla de "la novedad / del suceso más notable / que el vulgo, archivo confuso / califica en sus anales" (III, 628-631), así como don Gutierre, en el relato mentiroso que hace al rey, dice: "de la tragedia más rara, / escucha la admiración, / que eleva, admira y espanta”, (III, 775-777). El teatro del Siglo de Oro abunda en expresiones análogas, que confirman la importancia de la admiratio. La historia de los amantes de Teruel es, en la versión de Tirso, "la más prodigiosa historia / de amor que vieron jamás" Castilla y Aragón: "No muestra más / toda la antigua memoria"; la muerte por amor de Marsilla es "el caso más espantoso / que vio el mundo", etc. En cuanto al "cuerdamente / sus agravios satisfizo", dicho a continuación de "acción tan inclemente" (III, 744-745), es más que probable que esté dicho con ironía.

25 Op. cit., t. 2, p. 321.

26 "This lack of ciencia consciously accepted by Gutierre is his great fault", O'Connor, art. cit., p. 318. 
tendimiento hasta el punto de hacerle perder el control sobre su razón y su voluntad ${ }^{2 \tau}$. Creyendo ser razonable, cae sin darse cuenta en la racionalización de su locura: el papel que se inventa y que desempeña hasta sus últimas consecuencias es ya producto de su enajenación mental ${ }^{28}$.

Varios críticos han hablado del carácter patológico de don Gutierre. Entwistle lo llamó "sujeto... raro" 29 ; C. A. Jones, "a man with an obsession about honour" 30 ; D. Rogers, "a psychopath", "pathologically suspicious nature" 31 . Podríamos, entonces, asociarlo a los personajes extraños que hemos examinado antes; sería una figura marcada por una peculiar patología. Creo, sin embargo, que el caso es un tanto distinto, porque, como dije antes, aunque la suspicacia de don Gutierre queda apuntada en el primer acto, lo que verdaderamente importa, lo que Calderón desarrolla con espléndida maestría, es la transformación que se opera en él por obra de los celos. Este proceso dinámico, la repetida y creciente lucha interna entre la sensatez y la pasión, que culmina en la pérdida de la razón, es lo "admirable, prodigioso y espantoso" del personaje. O sea, que la caracterización, en el sentido limitado que he dado a la palabra, no se muestra aquí tanto en la creación de una personalidad singularizada como en la invención de un singular trastorno psicológico,

27 Wardropper ha estudiado el fenómeno de la turbación. "In this state, dice, right conduct is impossible; man is the victim of his repressed desires", su inconsciente sale a flote ("The unconscious mind in Calderón's El pintor de su deshonra", en H. Flasche (ed.), Calderón de la Barca (Darmstadt, 1971), 235-256; la cita, p. 238). E1 honor, dice más adelante, "is associated always with the conscious mind. It is properly under the control of the will" (p. 243). Parece, en efecto, que son los celos, no el honor, lo que turba el entendimiento de don Gutierre. E1 texto de la obra, las muchas alusiones a los celos en boca del protagonista y de otros personajes, lo revela con la claridad necesaria, y varios críticos lo han observado. Para Parker es "el espectro de los celos" lo que se interpone entre Gutierre y su razón; "el pensar que los celos podrán tener fundamento lo convierte de hombre racional en furia apasionada" (CH(1), p. 148) ; Rogers dice: "Jealousy (not honor) has crept in..." (supra y nota 18). La cuestión es importante. El médico de su honra se ha visto siempre como un caso extremo entre los dramas de honor, como -para citar a Reichenberger (art. cit., p. 308) - "the most telling representative" de las piezas en que la obediencia al código del honor "leads to supreme injustice". Sin embargo, lo que la obra nos muestra es a un médico de sus celos.

28 Cf. WARdropper, art. cit. de $C H(3)$, p. 929: "Libertada por completo de la realidad moral, su imaginativa se pone a crear un drama dentro del drama, una duplicación interior. Como si fuera actor, don Gutierre, noble andaluz, se transforma en otro don Gutierre, el que hace el papel metafórico de médico. Como un buen actor, cree en la realidad de la ficción dentro de la cual trabaja. Es ya algo que no ha existido nunca, el médico de su honra..."

29 "Honra y duelo", $R J, 3$ (1950), pp. $408 s$.

30 "Spanish honour...", art. cit. (supra, nota 4), pp. $35 \mathrm{~s}$.

31 Art. cit., pp. 276 s., 288. 
expuesto ante los ojos del espectador de una manera hondamente conmovedora.

Y está a la vista que este trastorno es el móvil básico de la acción en El médico de su honra ${ }^{32}$. Digo móvil básico porque no es el único: está la gran culpa de don Enrique y la pequeña culpa de Mencía (sus repetidas imprudencias); está también el azar, que conspira contra todos los personajes. Pero quizá Mencía no habría muerto si don Gutierre no hubiera enloquecido ${ }^{33}$.

Aquí tenemos una obra teatral cuya acción depende en lo fundamental de las vivencias internas de su protagonista y se subordina, por lo tanto, a la "caracterización". Nuevamente nos encontramos, pues, en conflicto con la idea aristotélica que preside buena parte de la crítica actual del antiguo teatro español. ¿Es que se trata de excepciones? Puede ser; pero no son tan pocas las comedias serias donde ocurre algo análogo. El propio Parker no ha podido menos de observar la fuerza que tienen ciertos personajes; al analizar $L a$ devoción de la cruz dice:

Curcio se presenta como un hombre que, de manera inmoderada y presuntuosa, está orgulloso de su nobleza y que, en consecuencia, tiene un concepto extravagante de su honor... orgullo egocéntrico..., toda la salvaje crueldad de un pundonor exagerado y egocéntrico... Esta presentación de un padre cruelmente egoísta es sumamente poderosa... Aislando el carácter, la conducta y los motivos de Curcio con respecto a los demás incidentes violentos de la acción dramática, nos damos cuenta de que aquéllos, y no éstos, son los más significativos ${ }^{34}$.

32 No el carácter mismo del personaje, como quiere O'ConNor cuando, hablando de éste - "a man whose basic flaw is his lack of trust, or better stated, his inability to trust anyone in matters concerning honor"- dice: "This attitude is the principal motivating force behind all of Gutierre's actions" (art. cit., p. 318).

33 Peter Dunn parece haber objetado anticipadamente mi interpretación cuando, en 1960, escribió: "I do not think that the tragedy finally depends on character, although character is part of the circumstances through which tragedy is realised. Indeed, the same terrible pattern is worked out in different plays. We might say that the violent energy of honor itself is the "efficient" cause, and the imprudence or other quality which attracts the violence is the "formal" cause. It makes no difference to honour whether this secondary cause is imprudence or ill-luck" ("Honour and the Christian background in Calderón", en B. W. WARDRopper (ed.), Critical essays..., op. cit., p. 39; la objeción va dirigida contra Wilson, quien había adjudicado a Mencía la culpa de su muerte). Pienso que, en el caso de don Gutierre, la factura misma de la obra muestra lo contrario. Ya apuntamos la gran diferencia entre El médico y El pintor, dos tragedias elaboradas sobre "the same terrible pattern".

34 "Bandits and saints in the Spanish drama of the Golden Age", en J. E. VAReY, Critical studies..., op. cit., pp. 158 s. (la traducción y las cursivas son mías). 
Pero además queda en entredicho, otra vez, la idea de la preponderancia del tema. ¿Cuál es el tema de El médico de su honra? ¿No se agota el "sentido" de esta obra en la presentación genial de una serie de sucesos impresionantes, notables, conmovedores, en cuyo centro está un gran personaje que vive un gran drama interno? ¿No se agota su sentido en lo que la obra es? La extraordinaria riqueza de un drama como El médico de su honra invita, por supuesto, a meditar una y otra vez sobre su sentido y a llegar a interpretaciones diversas, más o menos profundas, más o menos acertadas. Sería absurdo negar la licitud de tales intentos, en que el crítico, al trascender la vivencia directa de la lectura, penetra como aventurero en la intrincada selva de la obra de arte y se abre un camino. Pero tal pareçe que la selva vuelve a cerrarse siempre; y lo que queda finalmente es su exuberante e imperecedera vegetación.

Pienso que los cinco casos examinados aquí muestran a las claras que los grandes dramaturgos del Siglo de Oro español suelen prestar a sus personajes una atención paralela o superior a aquella que dedican a la acción y que no estamos tan equivocados como suponía Reichenberger "cuando esperamos encontrar más rasgos de carácter individualizadores y distintivos" de los normales en un cierto estado social $^{35}$. Al encontrarnos con esos personajes singularizados por un rasgo peculiar o por reacciones de una intensidad anómala y al interesarnos por ellos, abandonamos el terreno de las verdades universales en que se han venido desarrollando en los últimos años muchos estudios sobre la comedia, para adentrarnos en el mundo de lo individual, lo único, lo extraordinario. En aquél se cumple la misión de enseñar, en éste la de deleitar; "porque, como dice el Pinciano, la cosa nueva deleyta, y la admirable más, y más la prodigiosa y espantosa" 36 .

Decía también López Pinciano que el principal ornamento y arreo de la poética musa "es el milagro y maravilla" y que "los poemas que no traen admiración no mueven cosa alguna” (t. 2, p. 56). Las doce Novelas ejemplares de Cervantes son, en palabras

35 "The uniqueness...", art. cit., p. 311: "We are wrong, therefore, when we expect more individualizing distinctive traits of character than would be the normal, anticipated response to an outside stimulus in a person of a certain estado". Reichenberger subraya el carácter colectivo de los personajes: "One could almost say that there is only one protagonist in the Spanish comedia, the Spanish people. From king to peasant, each person exists primarily as a member of his community, to whom are assigned definite duties. A king has to act as a king - to dispense justice; the nobleman as a nobleman - to be a faithful vassal, or a reliable friend, or a passionate lover, the peasant as a peasant - to be proud, independent, and at the same time loyal to the king" (ibid., p. 305) .

36 Op. cit., t. 2, p. 58. 
de Casalduero, "doce maravillas"; lo son por los sucesos notables que relatan o por los personajes excepcionales que ponen en escena: "El licenciado Vidriera: raro cambio y perturbación de un estudiante... El celoso extremeño: extraordinario caso de celos" ${ }^{3 \pi}$. ¿Qué lección cabía sacar de la curiosa locura de Vidriera o de los exarcerbados celos de Carrizales? ¿Cuál enseñanza proporcionaba la terquedad de Juan Labrador, la desenfrenada inventiva de don García, la anormalidad de Serafina, la extrema bobería de Finea o la atormentada pasión celosa de don Gutierre? Ahí es el espectáculo -cómico o trágico- lo que cuenta, el espectáculo de un personaje curioso o conmovedor, siempre extraño. Ahí estamos en el "deleite" puro, estamos viendo y viviendo la carne y los nervios y la sangre de la obra de arte literaria.

MARgit Frenk

El Colegio de México.

37 J. Casalduero, Sentido y forma de las "Novelas ejemplares", 2a ed., Madrid, 1969, p. 25. 